\title{
The syllable's role in word naming
}

\author{
LUDOVIC FERRAND \\ C.N.R.S. and Université René Descartes, Paris, France \\ and University of Birmingham, Birmingham, England \\ JUAN SEGUI \\ C.N.R.S. and Université René Descartes, Paris, France \\ and \\ GLYN W. HUMPHREYS \\ University of Birmingham, Birmingham, England
}

\begin{abstract}
In a series of experiments, the masked priming paradigm with very brief prime exposures was used to investigate the role of the syllable in the production of English. Experiment 1 (word naming task) showed a syllable priming effect for English words with clear initial syllable boundaries (such as BALCONY), but no effect with ambisyllabic words targets (such as BALANCE, where the $/ \mathrm{V}$ belongs to both the first and the second syllables). Experiment 2 failed to show such syllable priming effects in the lexical decision task. Experiment 3 demonstrated that for words with clear initial syllable boundaries, naming latencies were faster only when primes formed the first syllable of the target, in comparison with a neutral condition. Experiment 4 showed that the two possible initial syllables of ambisyllabic words facilitated word naming to the same extent, in comparison with the neutral condition. Finally, Experiment 5 demonstrated that the syllable priming effect obtained for CV words with clear initial syllable boundaries (such as DIVORCE) was not due to increased phonological and/or orthographic overlap. These results, showing that the syllable constitutes a unit of speech production in English, are discussed in relation to the model of phonological and phonetic encoding proposed by Levelt and Wheeldon (1994).
\end{abstract}

What is the role of syllables in speech production? In a recent study, Ferrand, Segui, and Grainger (1996) demonstrated that French subjects responded faster in word, nonword-, or picture-naming tasks when the prime corresponded to the first syllable of the stimulus than when it corresponded to a longer or a shorter segment than the first syllable. Each prime corresponded to a complete syllable only in one of the two words: BA was exactly the first syllable of the word BA.LADE, ${ }^{1}$ but less than the first syllable of the word BAL.CON, whereas BAL was exactly the first syllable of BAL.CON, but more than the first syllable of BA.LADE. Thus the word BA.LADE was named faster when preceded by the prime BA than by BAL, whereas the word BAL.CON was named faster when preceded by the prime BAL than by BA. These results provide evidence for the syllable as a fundamental unit of speech production in French and mirror those obtained in speech perception (Mehler, Frauenfelder, Dommergues, \& Segui,

The research reported in this article was partially supported by a postdoctoral grant (COGNISCIENCES) to L.F. from the Centre National de la Recherche Scientifique (C.N.R.S.) and by an Economic and Social Research Council grant to G.W.H. A preliminary report of this study was presented at the European Summer School on "Aspects of Speech Production," held at the University of Birmingham, England, in July 1995. We thank Kathryn Spoehr, Arthur Samuel, Linda Wheeldon, Ardi Roelofs, and two anonymous reviewers for their comments on this work. Address correspondence to L. Ferrand, Laboratoire de Psychologie Expérimentale, C.N.R.S. and Université René Descartes, 28 rue Serpente, 75006 Paris, France (e-mail: ferrandl@idf.ext.jussieu.fr).
1981; Segui, 1984). Using a production variant of the classical syllable-monitoring task in speech perception (see Mehler et al., 1981), Wheeldon and Levelt (1995) replicated the syllable-monitoring effect in Dutch: responses to targets were faster when they corresponded to the initial syllable of the carrier word than when they did not. According to these authors, these results provide evidence that subjects base their responses on the generation of a syllabified phonological representation. Thus, the results obtained in French and Dutch suggest that syllables are functional units in speech production. Is this the case in English as well? This is an important question to address, since, as opposed to French, English has irregular syllable structures and frequently unclear syllable boundaries, a result of the widespread occurrence in English of ambisyllabicity in intervocalic consonants. Thus, in the present research, we addressed the possible role of syllables as functional units in the pronunciation of polysyllabic English words.

\section{Earlier Research on the Syllable's Role in English Naming}

While it seems plausible to assume that units smaller than syllables (phonemes, onsets, rimes) have independent status as units, this does not negate the possibility that syllable-sized units are also units of speech performance. Although speech errors involving complete syllables are relatively rare (Meyer, 1992; Shattuck-Hufnagel, 1979), there is evidence that such errors exist (Fromkin, 
1971; MacKay, 1972; Treiman, Straub, \& Lavery, 1994; Wells, 1951; Wijnen, 1988). For instance, Wells (1951) and Fromkin (1971) have reported such errors involving the substitution, omission, replacement, addition, etc., of one or more syllables, which further substantiates the claim that syllabic units are real performance units. Furthermore, according to Levelt (1989), all substitutions by monosyllabic morphemes are at the same time syllable replacements. Another indication of the role of syllabic units is MacKay's finding that in blends of polysyllabic words (i.e., combinations of words), the source words were more often broken between syllables than within syllables. Indeed, MacKay reported that $60 \%$ of breaks in multisyllabic words fall between syllables, whereas only $36 \%$ are expected by chance. Crompton (1981) reported haplologies (i.e., errors in which parts of intended utterances were missing) in which the missing part usually corresponded to one or more complete syllables. Furthermore, when a word is on the "tip of the tongue," speakers often know the number of syllables in the word even though they cannot retrieve the word itself (A. S. Brown, 1991; R. Brown \& McNeill, 1966). Together, these findings support the notion that the production of speech involves syllable-sized articulatory units.

The hypothesis that word naming involves syllablesized articulatory units has been recently challenged by some PDP models that deny such (as well as other) salient units, since in these types of models, symbolic representations such as syllables are lacking by definition (e.g., Seidenberg \& McClelland, 1989). According to Jared and Seidenberg (1990), syllable-like units would be an emergent property of Seidenberg and McClelland's model. Naming does not require the recovery of sublexical syllable units. In particular, Jared and Seidenberg used a priming paradigm to determine whether the syllable is a sublexical representation used in word naming. They hypothesized that, if words are broken down into syllables, then emphasing the syllable should result in faster reaction times than when the word is presented holistically. They observed that presenting the first syllable (for $250 \mathrm{msec}$ ) followed by the second resulted in equivalent naming times when compared to the whole-word condition, concluding that the syllable is not a functional unit in word naming. In several other studies the potential role of syllables in naming has been explored, by directly comparing monosyllabic and polysyllabic words, but these studies have yielded inconsistent results (see Henderson, 1982, for a review). For example, Klapp, Anderson, and Berrian (1973) reported that the time to start vocalization on a word-naming task was longer for two-syllable words than for one-syllable words (see also Butler \& Hains, 1979, and Eriksen, Pollack, \& Montague, 1970, for similar results). However, other studies have reported no effect of the number of syllables on the initiation of word naming (e.g., Forster \& Chambers, 1973; Frederiksen \& Kroll, 1976). More recent research conducted by Jared and Seidenberg (1990) indicates, however, a possible source of discrepancy between the results mentioned above. According to Jared and Seidenberg, studies ex- amining the effects of number of syllables on naming have yielded inconsistent results because none of these studies examined the interaction of word frequency and number of syllables on naming. Jared and Seidenberg showed that the number of syllables in a word influenced naming latencies only for low-frequency words.

However, in one recent study, Tousman and Inhoff (1992) have reported that the naming of a bisyllabic target word is facilitated by the prior presentation of clearly visible primes that corresponded to the first syllable of the targets. Tousman and Inhoff showed that the naming latencies of the word GLUCOSE, for example, were faster when the target was preceded by the presentation (for $250 \mathrm{msec}$ ) of a prime that corresponded to the first syllable (e.g., GLU) than when it was preceded by the presentation of a neutral prime (e.g., ---).

Therefore, studies examining syllabic effects in word naming in English have yielded rather inconsistent results. What could be the basis of these inconsistent results?

\section{Syllables in English}

The positioning of the syllable boundary in English is by no means clear-cut. In traditional treatments of English syllabification, a word such as TALCUM, in which the boundary between syllables is uncontroversial, would consist of two syllables, [TAL] and [CUM] (see Anderson \& Jones, 1974, for linguistic evidence, and Derwing, 1992, and Treiman \& Zukowski, 1990, for empirical evidence). This is due to the legality principle of syllabification (Hooper, 1972; Pulgram, 1970), which states that any consonants that begin a syllable within a word must be a legal onset. Likewise, any sequence of consonants that ends a syllable within a word must be a legal coda. For example, TALCUM cannot be broken before /1/ because $/ \mathrm{k} /$ is not a legal English onset. ${ }^{2}$ Another clear case of syllabification in English occurs when the primary stress falls on the second syllable, as in BABOON. All phonological theories (see Treiman \& Danis, 1988) appear to agree that the boundary must fall between the first vowel and the medial consonant (giving BA.BOON). However, English tends to have great variation in syllable weight, and syllable boundaries in English are frequently unclear. In particular, English has many words with ambisyllabic consonants, which are treated as part of the first as well as the second syllable (Fallows, 1981; Gussenhoven, 1986; Kahn, 1976; Treiman \& Danis, 1988). For instance, in the word BALANCE, in which the primary stress is on the initial syllable, the syllable boundary falls neither clearly before nor after the $/ 1 /$, because this intervocalic consonant can be legal in both word-initial and word-final positions. For English, there is agreement to treat these intervocalic consonants as ambisyllabic (see, however, Selkirk, 1982, who argued that the notion of ambisyllabicity is unnecessary). Phonologists represent the syllable structure of ambisyllabic English words such as BALANCE as [BA[L]ANCE], ${ }^{3}$ where the /1/ properly belongs to both first and second syllables (Anderson \& Jones, 1974; Bell \& Hooper, 1978). According to Cutler, Mehler, Norris, and Segui (1986, p. 396), "English ... has extremely 
irregular syllable structure, and frequently unclear syllable boundaries, particularly as a result of the widespread occurrence of ambisyllabicity in intervocalic consonants. Ambisyllabic consonants between the first and the second syllable of polysyllabic words - as in salat - are especially common." This peculiarity of English phonology might explain the rather inconsistent results obtained in naming experiments.

\section{The Present Study}

In the following experiments, we used the masked priming technique combined with the naming task (see Ferrand et al., 1996) to study the possible role of the syllable in speech production in English. In order to test the validity of the syllable as a unit of naming, we exploited the fact that, in English, words with the same initial phoneme sequence may have different initial syllables. Indeed, although the words BAL.CONY and BA[L]ANCE share the first three phonemes $/ \mathrm{b} /, / \mathfrak{a} /$, and $/ \mathrm{l} /$, their syllabic structures differ, such that BAL is exactly the first syllable of BAL.CONY and BA is less than the first syllable of BAL.CONY, whereas BA and BAL can both be the first syllable of $\mathrm{BA}[\mathrm{L}] \mathrm{ANCE}$. If syllables play a central role over and above phoneme units in naming, we should observe a facilitation when prime and target share phonemes that constitute a syllable unit as opposed to when prime and target share phonemes that do not constitute a syllable unit.

In this study, we compared words with ambisyllabic consonants (e.g., BA[L]ANCE) with words with unambiguous initial syllables (e.g., BAL.CONY). In BAL.CONY, for example, the syllabification is clear; there is a syllable boundary between BAL and CONY. According to linguistic and behavioral evidence (Treiman \& Danis, 1988; Treiman \& Zukowski, 1990), the boundary between the two syllables of CVC words is clear because the last consonant of the first syllable and the first consonant of the second syllable (e.g., /lk/ in BALCONY) do not form a legal word-initial cluster in English. By using stimuli with clear syllable boundaries, we gave the syllabification strategy the best possible chance to emerge. Thus, we might expect syllabifiable targets such as BALCONY to be named faster when preceded by BAL primes than when preceded by BA primes, but no differences in latencies for the two types of prime to be found with ambisyllabic targets such as BA[L]ANCE. Another possibility is that naming latencies for both types of target might be faster when primed by BAL primes than by BA primes, since BAL is the first syllable of BA[L]ANCE and it may also activate part of the second syllable as well (from the $/ \mathrm{l} /$ when the stimulus is parsed as BA.LANCE).

Thus, the purpose of the present research was (1) to find out whether the phonological codes that are generated from a masked prime are structured syllabically in English, (2) to compare words with ambiguous initial syllables (such as BALANCE) with words with unambiguous initial syllables (such as BALCONY), and (3) to identify the level(s) of processing (perceptual and/or articu- latory) where syllabic codes are involved in naming (if they are involved at all).

In the following experiments, the subject's task was to name words as quickly as possible, or to classify letter strings as words or nonwords rapidly. In Experiment 1, we extended the design of the original French study by Ferrand et al. (1996) by using words with clear initial syllable boundaries (such as BALCONY) and ambisyllabic words (such as BALANCE). In Experiment 2, we tested the same stimuli in the lexical decision task. In Experiment 3, we used CVC words with clear initial syllable boundaries, and we tested the nature (facilitatory or inhibitory) of this syllable priming effect by using a neutral baseline. In Experiment 4, we used ambisyllabic words to test the hypothesis that ambisyllabic words can be primed equally (or not) by their two possible initial syllables. Finally, in Experiment 5, we used CV words with clear initial syllable boundaries, and we tested the hypothesis that the syllable priming effect was due to increased phonological and/or orthographic overlap.

\section{EXPERIMENT 1 Naming}

\section{Method}

Subjects. Twenty psychology students at the University of Birmingham served as subjects for a small payment. All were native speakers of English, with normal or corrected-to-normal vision.

Stimuli and Design. Twenty pairs of English words sharing the same initial three phonemes (CVC) were taken from the stimuli used by Bradley, Sanchez-Casas, and Garcia-Albea (1993; see Appendix A). The words making up any pair began with a common CVC sequence but then diverged: One type had a clear syllable boundary after the initial CVC (e.g., BALCONY), whereas in the other member of the pair, the third phoneme was ambisyllabic - that is, the second consonant of the initial CVC could be said to belong to both syllables (e.g., BALANCE). Thus, in the pair BALCONY/BALANCE, the first three phonemes $/ \mathrm{b} / / \mathfrak{x} / / 1 /$ are identical. However, this CVC sequence forms a complete syllable in BALCONY, whereas BALANCE has an ambisyllabic [1]. These words were polysyllabic nouns or verbs (mean number of syllables 2.5 ; range, $2-3$ ), all of which had a primary stress on the initial syllable, and a stressless second syllable. The average frequencies were 21 occurrences per million for the CVC target words (ranging from a minimum of 1 to a maximum of 160 ) and 35 occurrences per million for the $\mathrm{CV}[\mathrm{C}]$ target words (ranging from a minimum of 1 to a maximum of 157; Francis \& Kučera, 1982). The range of segment types making up the common CVC sequences was as broad as possible. No constraints were placed on the first consonant (only 50\% were stops), and the sequence could continue with any of the short vowels $/ \mathfrak{a} /, / \mathrm{e} /, / \mathrm{i} /$, or $10 /$. The second consonant varied among the liquid $/ 1 /$, the nasals $/ \mathbf{n} /$ and $/ \mathrm{m} /$, and the fricative $/ \mathrm{s} /$. Each target word was presented twice to a given subject, paired with one of the two alternative primes in the first half of the experiment and with the other possible prime in the second half. The two categories of word targets (CVC and $\mathrm{CV}[\mathrm{C}]$ words) represented the factor type of target, whereas the two categories of prime stimuli ( $\mathrm{CVC} \% \% \%$ and $\mathrm{CV} \% \% \% \%$ primes) represented the factor type of prime. The type of target factor was crossed with the type of prime factor in a $2 \times 2$ factorial design. Two groups of subjects were used to counterbalance the presentation order of a given word target and its two corresponding primes. Thus, two orders of presentation were used, and each subject received all 
the priming conditions and saw the target words twice in either of the two orders.

Procedure. Stimuli were presented in isolation on the center of the display screen of a personal computer with a $70-\mathrm{Hz}$ refresh rate. The items appeared on the screen as white characters on a dark background. Each character (in uppercase) covered approximately $0.38^{\circ}$ of visual angle from the viewing distance of $60 \mathrm{~cm}$. The masked priming procedure with the naming task used in the experiments of Ferrand et al. (1996) was adopted here. Each trial consisted of the following sequence of four stimuli presented at the same screen location. Primes were always completely covered by the mask. First a forward mask consisting of a row of nine hash marks (\#\#\#\#\#\#) was presented for $500 \mathrm{msec}$. This was followed immediately by presentation of the prime for $29 \mathrm{msec}$, a backward mask (\#\#\#\#\#) for $14 \mathrm{msec}$, and, finally, presentation of the target word. The prime and target words were both presented at the same screen location as were the masks. The target remained on the screen until the subjects responded. Primes were always presented in lowercase and targets in uppercase. The subjects were asked to fixate the middle of the forward mask. They were also instructed to name the target word as rapidly and as accurately as possible. The existence of a prime was not mentioned. The computer recorded the naming times, measured from target onset to the triggering of the voice key by the subject's response. The experimenter sat in the same room as did the subject, in order to check and note responses. The next trial followed after a 2 -sec delay. Stimulus presentation was randomized, with a different order for each subject.

\section{Results}

Mean naming latencies are given in Figure 1. Latencies longer than $1,000 \mathrm{msec}$ were excluded (less than $1.5 \%$ ). The percentages of errors were $4.2 \%, 4.0 \%, 4.0 \%$, and $3.9 \%$ for $\mathrm{CVC}$ word targets primed by $\mathrm{CV}$ primes and $\mathrm{CVC}$ primes, and for $\mathrm{CV}[\mathrm{C}]$ word targets primed by $\mathrm{CV}$ primes and CVC primes, respectively. An analysis of variance (ANOVA) of correct reaction times (RTs) was run with type of target (CVIC] or CVC words) and type of prime (CV or CVC primes) entered as main factors. $F$ values are reported by subjects $\left(F_{1}\right)$ and by items $\left(F_{2}\right)$.

The main effect of type of target was not significant $\left[F_{1}(1,19)=1.34\right.$ and $\left.F_{2}(1,19)=1.51\right]$, but the main ef-

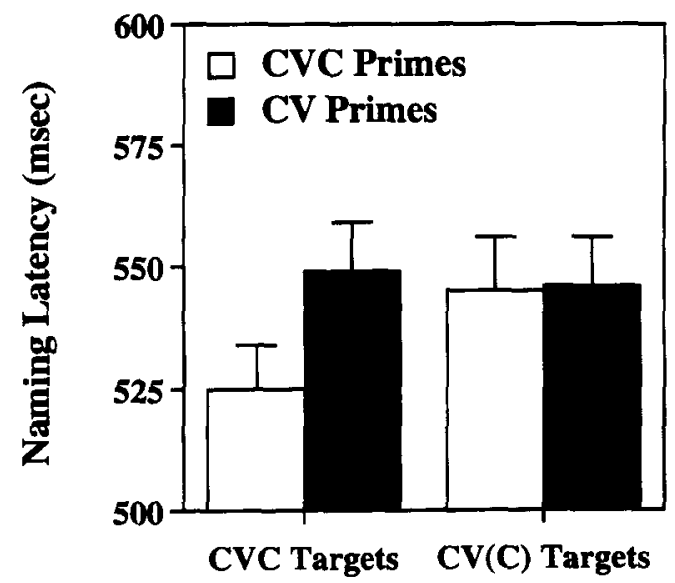

Figure 1. Mean naming latencies (in milliseconds) in Experiment 1 for $\mathrm{CVC}$ and $\mathrm{CV}[\mathrm{C}]$ words as a function of prime type (CVC or $\mathrm{CV}$ primes). Vertical bars represent standard errors. fect of type of prime was significant $\left[F_{1}(1,19)=21.67\right.$, $p<.001$ and $\left.F_{2}(1,19)=14.24, p<.001\right]$. The interaction of target and prime type was also significant $\left[F_{1}(1,19)=\right.$ $7.41, p<.02$ and $\left.F_{2}(1,19)=7.64, p<.02\right]$. The results show faster naming latencies when $\mathrm{CVC}$ word targets are preceded by CVC primes than when they are preceded by CV primes $\left[F_{1}(1,19)=14.99, p<.001\right.$ and $F_{2}(1,19)=$ $11.15, p<.005]$. However, naming latencies are not faster for $\mathrm{CV}[\mathrm{C}]$ word targets when they are preceded by $\mathrm{CV}$ primes that when they are preceded by CVC primes (both $F \mathrm{~s}<1$ ). An analysis of the error data showed no main effects or interactions (all $F \mathrm{~s}<1$ ).

\section{Discussion}

The results show a syllabic priming effect with syllabifiable CVC word targets (such as BALCONY), but no effect with ambisyllabic CV[C] word targets (such as BALANCE). These results may suggest that English subjects apply syllabification where it is appropriate (i.e., to words that are easy to syllabify), and not where it would be inefficient (i.e., to those words with ambisyllabic consonants). This pattern of results could explain why most of the previous studies conducted in English failed to reveal any syllabic effect, since in these studies, the factor ambisyllabicity was not controlled. Indeed, we have demonstrated clear syllabic effects with syllabifiable words, but not with words containing ambisyllabic consonants. The results obtained for CVC targets replicate those obtained in French by Ferrand et al. (1996). Note, though, that the effects with ambisyllabic words are more difficult to interpret. Any overall RT contrast between these target words and CVC targets could reflect differences between the word sets. It may be that both CV and CVC primes facilitate the naming of ambisyllabic words, or it may be that neither has an effect. This was examined in more detail in Experiment 4, where we incorporated a neutral prime baseline.

The results of Experiment 1 could also be given an alternative explanation. It could be argued that subjects divide words at the point where the associations between adjacent letters are weakest (Adams, 1981). For example, subjects could break BALCONY between $\mathrm{L}$ and $\mathrm{C}$ because the frequency of the LC bigram is lower than the frequencies of the AL and co bigrams. This hypothesis was partially supported. Statistical analyses confirmed the existence of a bigram "trough" at the critical CC bigram as compared with the preceding and following bigrams for CVCC targets (such as BALCONY). According to the Solso and Juel (1980) bigram counts, the differences between the $\mathrm{CC}$ bigram (with a mean frequency of 387 ) and the preceding (mean frequency $=768$ ) and following (mean frequency $=761$ ) bigrams for CVC targets were significant (for both analyses, $p<.01$ ). However, for CV[C]V targets (such as BALANCE), the only significant difference was between the [C]V bigram and the preceding bigram (996 vs. 400 ), and the difference between the $[\mathrm{C}] \mathrm{V}$ bigram and the following bigram was not significant ( $400 \mathrm{vs.} 500$ ). Although the frequencies of 
the $\mathrm{CC}$ and [C]V bigrams were significantly lower than those of the preceding bigrams, the priming data obtained in Experiment 1 are inconsistent with the bigram frequency hypothesis. According to the bigram frequency hypothesis, subjects should have divided words at the point where the associations between adjacent letters were weakest. Whereas this seems to have been the case for the CVC targets, it was not the case for the CV[C] targets. It should be mentioned at this point that the results obtained by Treiman and Danis (1988) and Rapp (1992) do not support this explanation of the results in terms of bigram troughs.

One possible locus of this apparent syllabic facilitation effect for CVC targets is at the level of speech output units that store motor control programs allowing the physical realization of speech sounds. The existence of syllable-sized output units (cf. Levelt \& Wheeldon, 1994) within the theoretical framework for word and picture naming sketched by Ferrand, Grainger, and Segui (1994) could explain the syllabic priming effects observed in Experiment 1. Sublexical orthographic units that are activated upon prime presentation will send activation directly to the syllabic output units, thus facilitating the pronunciation of any target stimulus that shares the same syllable units.

An alternative explanation of the results of Experiment 1 would be that initial syllables are access codes for visual word recognition (see, e.g., Spoehr \& Smith, 1973; Taft, 1979; Taft \& Forster, 1976) and that presentation of a prime stimulus that corresponds to a word's initial syllable facilitates the retrieval of the corresponding lexical representation. The access code involved could be either visual (cf. Taft, 1979) or phonological in nature (Spoehr \& Smith, 1973). In either case, activation of the access process by the syllable unit would lead to faster wordnaming latencies as long as word naming is at least partly dependent on lexical retrieval. This hypothesis was tested previously in French in a lexical decision task (Ferrand et al., 1996).

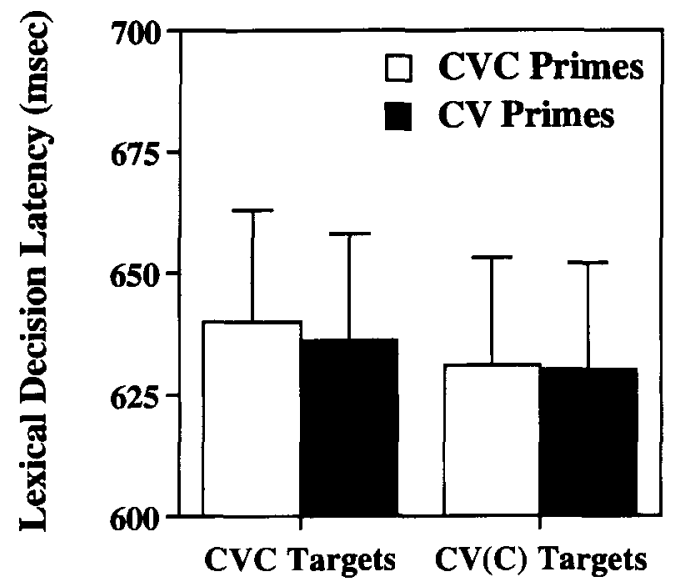

Figure 2. Mean lexical decision times (in milliseconds) in Experiment 2 for $\mathrm{CVC}$ and $\mathrm{CV}[\mathrm{C}]$ words as a function of prime type (CVC or CV primes). Vertical bars represent standard errors.

\section{EXPERIMENT 2 \\ Lexical Decision Locus of the Effect}

To provide a further test of the hypothesis that the locus of the syllable priming effect is in output rather than visual or phonological access processes, in Experiment 2 we used a task-namely, lexical decision-that does not require that the target's phonology be output. Nevertheless, previous work has shown that both visual and phonological lexical representations can be activated automatically when lexical decisions are made to targets subject to masked priming (e.g., Grainger \& Ferrand, 1994, 1996). If speech output processes are the locus of syllable priming, one should not observe the syllable priming effect for word targets in lexical decision. On the other hand, if the syllable priming effect affects lexical access processes, it should be observable in the lexical decision task.

\section{Method}

Subjects. Twenty additional psychology students at the University of Birmingham served as subjects for a small payment. All were native speakers of English, with normal or corrected-to-normal vision. None had taken part in Experiment 1.

Stimuli and Design. The word targets were exactly the same as in Experiment 1. Twenty nonword targets were constructed for the purposes of the lexical decision task. ${ }^{4}$ The nonwords were generated from English words by replacing (after the first three phonemes) a consonant with another consonant, or a vowel with another vowel, in such a way that only legal syllables in English were used.

Procedure. The procedure was the same as that of Experiment 1, except that the task was a lexical decision task. The subjects were instructed to respond as rapidly and as accurately as possible whether or not the letter string in uppercase that remained on the screen was an English word. The subjects responded "yes" by pressing one of the two response buttons with the forefinger of the preferred hand and "no" by pressing the other response button with the forefinger of the nonpreferred hand.

\section{Results}

Mean lexical decision latencies are given in Figure 2 for word targets. Latencies longer than $1,000 \mathrm{msec}$ were excluded (less than $2 \%$ ). The percentages of errors were $10.0 \%, 10.5 \%, 11.0 \%$, and $12.0 \%$ for CVC word targets primed by $\mathrm{CV}$ primes and $\mathrm{CVC}$ primes and for $\mathrm{CV}[\mathrm{C}]$ word targets primed by $\mathrm{CV}$ primes and $\mathrm{CVC}$ primes, respectively. An ANOVA of the correct RTs was run for word targets with type of target (CV[C] or CVC targets) and type of prime (CV or CVC primes) entered as main factors.

In an ANOVA conducted on the word RTs and error data, no main effect or interaction reached the .05 level of significance in either analysis (by subjects or by items, all $F \mathrm{~s}<1$ ).

\section{Discussion}

The same stimuli that produced a syllabic priming effect in the naming task of Experiment 1 did not produce a similar effect in the lexical decision task of Experiment 2 . This null result provides further support for the hypothesis that the syllable priming effect observed in 
Experiment 1 lies in output rather than lexical access processes (see also Ferrand et al., 1996, for a similar result obtained in French). The fact that we did not observe syllabic priming effects in the lexical decision task does not, of course, imply that this task is insensitive to either visual or phonological priming from masked letter strings. With monosyllabic word targets, Ferrand and Grainger (1992, 1993, 1994; see also Grainger \& Ferrand, 1996) have consistently observed masked orthographic and phonological priming effects (primes were pseudohomophones of the target) in lexical decision. However, whereas orthographic priming effects appeared with prime exposures similar to those used in the present experiments, phonological priming effects required longer prime exposures (see Ferrand \& Grainger, 1993). Therefore, it is possible that phonologically based syllabic priming effects would appear in the lexical decision task with longer prime exposure durations, if such sublexical input phonology is structured syllabically. The point, however, in demonstrating that there is no syllabic effect in the lexical decision task when one is using exactly the same presentation conditions that allowed the effects to emerge in word naming is to rule out an access code account of the word-naming results.

Indeed, the work of Spoehr and Smith (1973; see also Spoehr, 1978, 1981) does suggest that syllable-sized units play a role in visual word report. Subjects were presented with five-letter English words that were either one or two syllables long and that were matched in pairs for other variables such as frequency and number of vowels (e.g., PAINT and PAPER). These authors showed that report accuracy was significantly higher for one- than for twosyllable words. These results suggest that processing in this task proceeds syllable by syllable.

\section{EXPERIMENT 3 Naming Neutral Baseline}

In Experiment 3, syllabic priming effects were measured against a neutral baseline condition (composed of percent signs) in order to test the nature (facilitatory or inhibitory) ${ }^{5}$ of the syllabic priming effect observed with CVC word targets in Experiment 1 (words with clear initial syllable boundaries). As in Experiment 1, we used word targets with clear initial syllable boundaries. For each target word, three types of prime were selected: (1) primes that shared exactly the first syllable of the target; (2) primes that shared the first two phonemes with the target; and (3) neutral primes (composed of percent signs).

\section{Method}

Subjects. Twenty-one additional psychology students at the University of Birmingham served as subjects for a small payment. All were native speakers of English, with normal or corrected-to-normal vision. None had taken part in the previous experiments.

Stimuli and Design. Twenty-four CVC English words (with clear initial syllable boundaries) as in Experiment 1 were taken from Bradley et al. (1993; see Appendix A). For each target word, three types of primes were selected: (1) primes that shared exactly

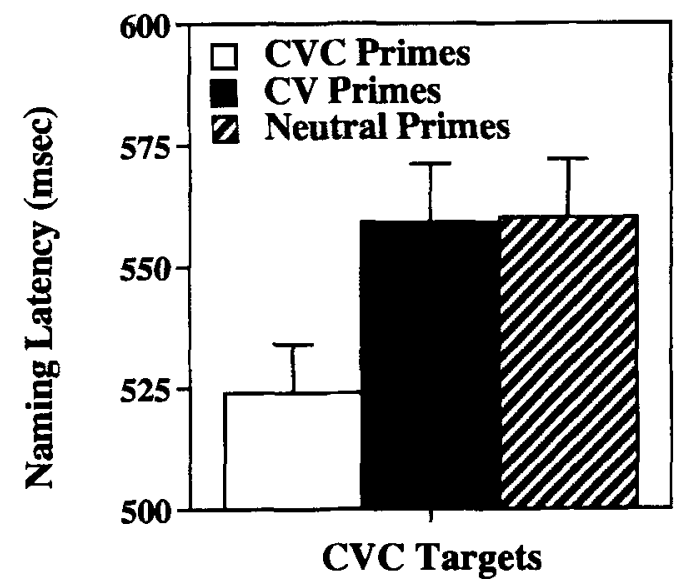

Figure 3. Mean naming latencies (in milliseconds) in Experiment 3 for CVC words as a function of prime type (CVC, CV, or neutral primes). Vertical bars represent standard errors.

the same first syllable with the target (e.g., bal\%\%\%\%-BALCONY); (2) primes that shared less than the first syllable with the target (e.g., ba $\% \% \% \% \%$-BALCONY); and (3) neutral primes (e.g., $\% \% \% \% \% \% \%$ BALCONY). The average frequency was 24 occurrences per million for the CVC target words (ranging from a minimum of 1 to a maximum of 160; Francis \& Kučera, 1982). Prime-target pairs were rotated across the priming conditions across three groups of subjects, so that no subject saw any single prime or target word more than once but each subject received all three experimental conditions. Every subject saw 24 prime/word target pairs, 8 in each condition.

Procedure. The procedure was exactly the same as that of Experiment 1 .

\section{Results}

Mean naming latencies are given in Figure 3. Latencies longer than $1,000 \mathrm{msec}$ were excluded (fewer than $1 \%$ ). The percentages of errors were $3.0 \%, 3.5 \%$, and $3.8 \%$ for $\mathrm{CVC}$ word targets primed by $\mathrm{CVC}, \mathrm{CV}$, and neutral primes, respectively. An ANOVA was run on the correct RTs with type of prime $(\mathrm{CV}, \mathrm{CVC}$, or neutral primes) entered as the main factor. $F$ values are reported by subjects $\left(F_{1}\right)$ and by items $\left(F_{2}\right)$.

The main effect of type of prime was significant $\left[F_{1}(2,36)=38.51, p<.001\right.$ and $F_{2}(2,46)=7.71, p<$ $.005]$. Planned comparisons indicated that $\mathrm{CVC}$ primes facilitated CVC target naming relative to both the $\mathrm{CV}$ primes $\left[F_{1}(1,18)=113.68, p<.001\right.$ and $F_{2}(1,23)=$ $6.57, p<.02]$ and neutral primes $\left[F_{1}(1,18)=55.26, p<\right.$ .001 and $\left.F_{2}(1,23)=33.46, p<.001\right]$. CV primes, on the other hand, did not affect $C V C$ target processing relative to neutral primes $\left[F_{1}(1,18)<1\right.$ and $\left.F_{2}(1,23)<1\right]$. An analysis of the error data showed no effects (all $F \mathrm{~s}<1$ ).

\section{Discussion}

For words with clear initial syllable boundaries (e.g., BALCONY), the results clearly demonstrate that naming latencies were significantly faster only when prime stimuli formed the first syllable of the target. These results suggest that the syllabic priming effects obtained in Ex- 
periment 1 were indeed facilitatory effects. Compared with neutral primes, primes sharing the first syllable with targets facilitated naming performance, whereas primes corresponding to less than the first syllable failed to facilitate or inhibit naming performance. However, from this study alone it could be that CVC primes were more effective than $\mathrm{CV}$ primes simply because of increased phonological and/or orthographic overlap, not because of their status as the target word's first syllable. The special role of syllables in producing facilitation priming was tested further with ambisyllabic target words (Experiment 4 ) and $C V$ target words with clear initial syllable boundaries (Experiment 5). For ambisyllabic stimuli, $\mathrm{CV}$ and $\mathrm{CVC}$ primes should be equally effective, ruling out the possibility that increased phonological and/or orthographic overlap was responsible for the results with CVC primes in Experiment 3. For CV stimuli with clear initial syllable boundaries $\mathrm{CV}$ primes should be more effective than CVC primes because of their status as the target word's first syllable.

\section{EXPERIMENT 4 Ambisyllabicity}

In Experiment 4, syllabic priming effects were measured against a neutral baseline condition (composed of percent signs) in order to test the hypothesis that ambisyllabic words could be primed equally (or not) by their two possible initial syllables. Only the ambisyllabic word targets of Experiment 1 were used. For each target word, three types of prime were selected: (1) primes that shared their first three phonemes with the target; (2) primes that shared their first two phonemes with the target; and (3) neutral primes (composed of percent signs). Note that for these ambisyllabic words such as BALANCE, BA, and BAL can both constitute the first syllable (Anderson \& Jones, 1974; Kahn, 1976).

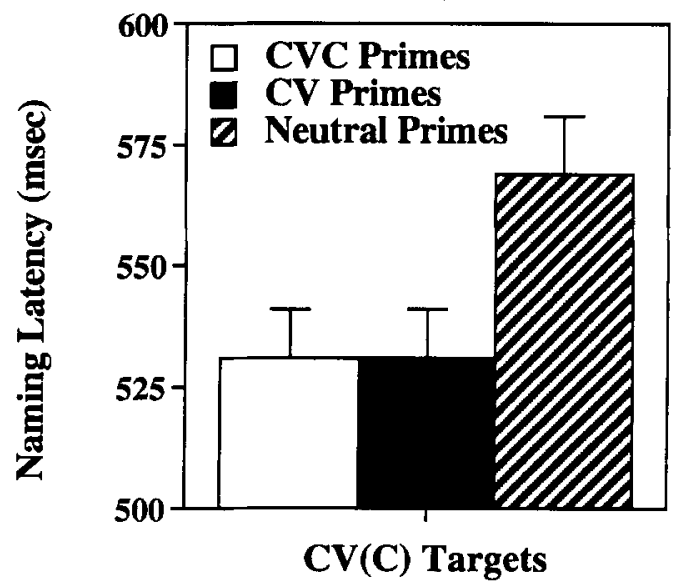

Figure 4. Mean naming latencies (in milliseconds) in Experiment 4 for $\mathrm{CV}[\mathrm{C}]$ words as a function of prime type (CVC, $\mathrm{CV}$, or neutral primes). Vertical bars represent standard errors.

\section{Method}

Subjects. Twenty-one additional psychology students at the University of Birmingham served as subjects for a small payment. All were native speakers of English, with normal or corrected-tonormal vision.

Stimuli and Design. Twenty-four ambisyllabic English words were taken from Bradley et al. (1993; see Appendix A). As in Experiment 1 , the word targets had the third phoneme ambisyllabic (e.g., BALANCE). For each target word, three types of primes were selected: (1) primes that shared their first three phonemes with the target (e.g., bal\%\%\%\%-BALANCE); (2) primes that shared their first two phonemes with the target (e.g., ba $\% \% \% \% \%$-BALANCE); and neutral primes (e.g., $\% \% \% \% \% \% \%$-BALANCE). The average frequency was 30 occurrences per million for the CV[C] target words (ranging from a minimum of 1 to a maximum of 157; Francis \& Kučera, 1982). Prime-target pairs were rotated across the priming conditions across three groups of subjects, so that no subject saw any single prime or target word more than once but each subject received all three experimental conditions. Every subject saw 24 prime/word target pairs, 8 in each condition.

Procedure. The procedure was exactly the same as that of Experiment 1 .

\section{Results}

Mean naming latencies are given in Figure 4. Latencies longer than $1,000 \mathrm{msec}$ were excluded (less than $1 \%$ ). The percentage of errors were $3.2 \%, 3.5 \%$, and $4.0 \%$ for $\mathrm{CV}[\mathrm{C}]$ word targets primed by $\mathrm{CVC}, \mathrm{CV}$, and neutral primes, respectively. An ANOVA was run on the correct RTs with type of prime (CV, CVC, or neutral primes) entered as the main factor. $F$ values are reported by subjects $\left(F_{1}\right)$ and by items $\left(F_{2}\right)$.

The main effect of type of prime was significant $\left[F_{1}(2,36)=38.57, p<.001\right.$, and $F_{2}(2,46)=18.41, p<$ $.001]$. Planned comparisons indicated that, relative to neutral primes, both CVC primes $\left[F_{1}(1,18)=50.07, p<\right.$ .001 , and $\left.F_{2}(1,23)=26.81, p<.001\right]$ and $C V$ primes facilitated target naming $\left[F_{1}(1,18)=67.24, p<.001\right.$, and $\left.F_{2}(1,23)=29.10, p<.001\right]$. However, CVC primes did not differ significantly from $C V$ primes $\left[F_{1}(1,18)<1\right.$ and $\left.F_{2}(1,23)<1\right]$. An analysis of the error data showed no effects (all $F$ s $<1$ ).

\section{Discussion}

The results show that the two possible initial syllables of ambisyllabic words facilitated word naming to the same extent, in comparison with the neutral condition. According to some linguists (Anderson \& Jones, 1974; Kahn, 1976), ambisyllabicity assigns a consonant to both syllables, implying equal importance of initial and final positions. The strongest arguments are phonetic (see Fujimura \& Lovins, 1978), maintaining that certain sounds like the $/ 1 /$ in BALANCE have properties that are both onset-like and coda-like. The present results provide experimental evidence for this linguistic theory of syllabification (Anderson \& Jones, 1974; Kahn, 1976). The data also show that the facilitation effects of just $\mathrm{CVC}$ primes in Experiment 3 was not due to their greater phonological/orthographic overlap, since CV primes here were shown to be as effective as CVC primes. 


\section{EXPERIMENT 5 CV Words}

In Experiment 5, we used CV word targets with clear initial syllable boundaries to further demonstrate that the syllable priming effect observed in Experiments 1 and 3 was not due to increased phonological/orthographic overlap. Indeed, in the previous experiments with CVC targets, it could have been that CVC primes were more effective than CV primes simply because of increased phonological and/or orthographic overlap, not because of their status as the target word's first syllable. Using CV word targets with clear initial syllable boundaries and showing an advantage of the syllable in this condition should rule out the possibility that increased phonological/orthographic overlap was responsible for the syllable priming effect. For each CV target word, three types of prime were selected: (1) primes that shared exactly the first syllable of the target; (2) primes that shared more than the first syllable with the target (the first three phonemes); and (3) neutral primes (composed of percent signs).

\section{Method}

Subjects. Twenty-one additional psychology students at the University of Birmingham, England, served as subjects for a small payment. All were native speakers of English, with normal or correctedto-normal vision. None had taken part in the previous experiments.

Stimuli and Design. Twenty-four CV English words (with clear initial syllable boundaries) were taken from Treiman and Danis (1988; see Appendix B). These words had a clear syllable boundary after the initial CV (e.g., DIVORCE), according to linguistic and behavioral evidence reported by Treiman and Danis (1988) and Derwing (1992). All phonological theories appear to agree that for $\mathrm{CV}$ words with primary stress on the second syllable the boundary must fall between the first vowel and the medial consonant (giving DI.VORCE). These words were polysyllabic nouns or verbs (mean number of syllables, 2.4 ; range, 2-3) that all had primary stress on the second syllable and had a medial consonant spelled with a single letter. The average frequency was 37 occurrences per million for the $\mathrm{CV}$ target words (ranging from a minimum of 1 to a maxi-

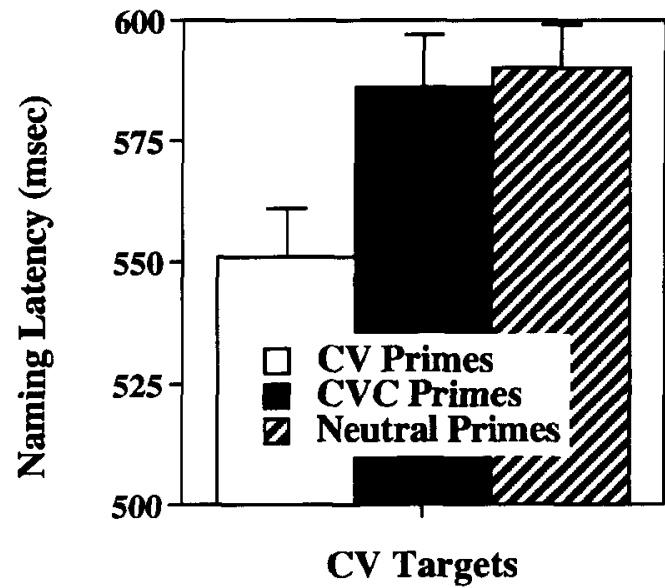

Figure 5. Mean naming latencies (in milliseconds) in Experiment 5 for $\mathrm{CV}$ words as a function of prime type $(\mathrm{CV}, \mathrm{CVC}$, or neutral primes). Vertical bars represent standard errors. mum of 174; Francis \& Kučera, 1982). For each target word, three types of primes were selected: (1) primes that shared exactly the same first syllable with the target (e.g., di $\% \% \% \% \%$-DIVORCE); (2) primes that shared more than the first syllable with the target (e.g., div $\% \% \% \%$-DIVORCE); and (3) neutral primes (e.g., $\% \% \% \% \% \% \%$ DIVORCE). Prime-target pairs were rotated across the priming conditions across three groups of subjects, so that no subject saw any single prime or target word more than once but each subject received all three experimental conditions. Every subject saw 24 prime/ word target pairs, 8 in each condition.

Procedure. The procedure was exactly the same as that of Experiment 1.

\section{Results}

Mean naming latencies are given in Figure 5. Latencies longer than $1,000 \mathrm{msec}$ were excluded (less than $1 \%$ ). The percentage of errors were $2.9 \%, 3.5 \%$, and $4.2 \%$ for $\mathrm{CV}$ word targets primed by $\mathrm{CV}, \mathrm{CVC}$, and neutral primes, respectively. An ANOVA was run on the correct RTs with type of prime (CVC, CV, or neutral primes) entered as the main factor. $F$ values are reported by subject $\left(F_{1}\right)$ and by items $\left(F_{2}\right)$.

The main effect of type of prime was significant $\left[F_{1}(2,36)=25.26, p<.001\right.$, and $F_{2}(2,46)=11.46, p<$ $.001]$. Planned comparisons indicated that $C V$ primes facilitated $\mathrm{CV}$ target naming relative to both the $\mathrm{CVC}$ primes $\left[F_{1}(1,18)=43.44, p<.001\right.$, and $F_{2}(1,23)=17.03, p<$ $.001]$ and neutral primes $\left[F_{1}(1,18)=52.19, p<.001\right.$, and $\left.F_{2}(1,23)=14.47, p<.001\right]$. CVC primes, on the other hand, did not affect $\mathrm{CV}$ target processing relative to neutral primes $\left[F_{1}(1,18)<1\right.$ and $\left.F_{2}(1,23)<1\right]$. An analysis of the error data showed no effects (all $F_{\mathbf{S}}<1$ ).

\section{Discussion}

For CV words with clear initial syllable boundaries (e.g., DIVORCE), the results clearly demonstrate that naming latencies were significantly faster only when prime stimuli formed the first syllable of the target. Compared with neutral primes, primes sharing the first syllable with targets facilitated naming performance, whereas primes corresponding to more than the first syllable failed to facilitate or inhibit performance. Therefore, from this study, it cannot be argued that the syllable priming effect obtained in Experiments 1 and 3 was due to increased phonological and/or orthographic overlap; instead, CVC primes were more effective than $\mathrm{CV}$ primes because of their status as the target word's first syllable.

\section{GENERAL DISCUSSION}

In five experiments, we investigated syllable priming effects in English, and the data from all five provide compelling evidence in favor of the syllable's role in naming in English. In Experiment 1, we replicated the design of the French experiment by Ferrand et al. (1996) including ambisyllabic word targets. For CVC words with clear initial syllable boundaries, primes were more effective when they constituted the first syllable of the target than when they were only phonologically related (with 
$\mathrm{CVC}$ as opposed to $\mathrm{CV}$ primes). For target words with ambisyllabic consonants, there were no differences between the effects of CVC and CV primes. However, this could have been because neither prime type was effective or because both were effective. In Experinient 2, we failed to observe such syllable priming effects in the lexical decision task. In Experiment 3, we tested the nature (facilitatory or inhibitory) of such syllable priming effects observed for CVC words with clear initial syllable boundaries by introducing a neutral condition. Naming latencies were consistently shorter in comparison with a neutral condition only when primes formed the first syllable of the target. However, it could have been that CVC primes were more effective than $\mathrm{CV}$ primes simply because of increased phonological and/or orthographic overlap, not because of their status as the target word's first syllable. In Experiment 4, we tested the hypothesis that ambisyllabic words can be primed equally (or not) by their two possible initial syllables. The results showed that the two possible initial syllables of ambisyllabic words facilitated word naming to the same extent in comparison with the neutral condition. Finally, in Experiment 5, we tested the hypothesis that the syllable priming effect obtained in Experiments 1 and 3 was simply due to increased phonological and/or orthographic overlap. The results demonstrated that the syllabic priming effect obtained for $\mathrm{CV}$ words with clear initial syllable boundaries (such as DIVORCE) was not due to increased phonological and/ or orthographic overlap, since $\mathrm{CV}$ primes were more effective than CVC primes. So, English speakers are clearly sensitive to the syllables of word targets to be named, and this hold for the unambiguous as well as for the ambisyllabic words.

The results of the present experiments demonstrate that briefly presented masked primes corresponding to the initial syllable of word targets facilitate the naming of these targets in English. On the other hand, the same prime stimuli did not affect performance to word targets in a lexical decision task. Furthermore, these syllabic priming effects were facilitatory in nature. All these results converge to suggest that the syllabic priming here is located at the level of output speech. An alternative explanation in terms of syllabically structured visual or phonological access codes in visual word recognition (Spoehr \& Smith, 1973; Taft, 1979; Taft \& Forster, 1976) fails to account for the absence of syllabic priming effects in the lexical decision task. In all cases in which a syllabic effect was observed, subjects had to produce an articulatory output, implying that it is the units involved in generating such an articulatory output that are structured syllabically.

Within the theoretical framework for word and picture naming presented by Ferrand et al. (1994), this rapid activation of output phonology arises via the direct connection between orthographic input units (i.e., letter or letter cluster codes) and speech output units. When a prime stimulus corresponds to the initial syllable of the following target, the appropriate initial syllable unit will be activated for articulatory output, thus allowing a faster generation of the target's articulatory output than when the prime does not correspond to the target's initial syllable. In order to explain the fact that the two possible initial syllables of ambisyllabic words facilitated word naming to the same extent in comparison with the neutral condition (Experiment 4), we have to modify Ferrand et al.'s (1994) model. In particular, we have to postulate that the two possible corresponding articulatory programs of ambisyllabic words are available each time we have to produce these words.

\section{The Syllable's Role in the Production of English, French, and Dutch}

Although English and French differ with respect to syllable structure (irregular vs. regular), syllable boundaries (unclear vs. clear), and ambisyllabicity (widespread vs. minimal), we have demonstrated that English speakers behave as French speakers do when confronted with words with clear initial syllable boundaries. The results of the present experiments are compatible with the general hypothesis that the syllable constitutes a unit of speech production in English. Taken together, the present results obtained in English, the results obtained in French by Ferrand et al. (1996), and the results obtained in Dutch by Levelt and Wheeldon (1994) and Wheeldon and Levelt (1995) strongly suggest that the syllable is indeed a basic unit of speech production across languages.

\section{Relation to Speech Perception in English}

In contrast to the present results obtained in speech production, several studies of speech perception have shown that syllables do not play a role in tasks in which native speakers of English monitor for fragments such as /bæ/ and /bæl/ (see Bradley et al., 1993; Cutler et al., 1986). These results suggest that native speakers of English do not instantaneously use the syllable as an immediate segmentation unit. However, syllables may become important at later stages of processing. For instance, Bruck, Treiman, and Caravolas (1995) found evidence for a role of syllables in a nonword comparison task. In this task, subjects were asked to judge whether two successively presented nonwords had sounds in common at the beginning, in the middle, or at the end. For all three locations, judgments were faster when the nonwords shared phonemes that constituted a syllable than when the nonwords shared phonemes that constituted only part of a syllable. In an auditory lexical decision task, Corina (1992) found also significant priming for words that shared their complete first syllables (such as pamper and pamphlet). However, no priming was observed for words that shared the same number of initial phonemes but that did not share their entire first syllables (such as blizzard and blister). Syl-lables also play a role in metalinguistic tasks (see, e.g., Treiman \& Danis, 1988; Treiman \& Zukowski, 1990). Thus, although research on speech perception has shown that ambisyllabicity may undermine the role of syllabic units in English (e.g., Bradley et al., 1993; Cutler 
et al., 1986), it is interesting to see that this is not the case with speech production.

\section{Levelt's Model of Phonological and \\ Phonetic Encoding}

Levelt $(1989,1992,1993$; Levelt \& Wheeldon, 1994) has proposed a model of phonological and phonetic encoding in which each speaker would possess a mental syllabary (i.e., a library of syllable-sized motor programs) that stores motor programs corresponding to all the syllables of the language. According to Levelt, the construction of successive syllables is central to phonological encoding. ${ }^{6}$ One argument for the existence of a syllabary is that syllables are real units of articulation (Fry, 1964; Fujimura \& Lovins, 1978). Moreover, most syllables are highly overused units of articulation, so it would be wasteful to fully program them time and again (Levelt, 1993). A first step in phonological encoding is the activation of a selected word's form in the mental lexicon. Two kinds of phonological information become available. The first is the word's segmental composition - roughly, the string of phonemes it consists of. The second is the word's metrical or foot structure: this is the word's syllabicity (the number of syllables that the word contains) and the word's stress pattern. The next step in phonological encoding is the association of spelled-out segments to the metrical frame of the corresponding phonological word. The eventual output of phonological encoding is a (metrically structured) string of phonological syllables which will be used to address the syllabary (Levelt \& Wheeldon, 1994). As phonological syllables are generated one after another, they will function as access codes to the syllabary. Access to the syllabary would be governed by the same principles that govern access to the lexicon; that is, a syllable would be all the more easily accessed the more frequently it is used. Levelt and Wheeldon tested this syllabary hypothesis on the basis of its prediction of a syllable frequency effect. Subjects had to produce bisyllabic words in response to abstract visual patterns that they had learned to associate with these words. The authors used four types of words: low-frequency words with low-frequency syllables, low-frequency words with high-frequency syllables, high-frequency words with low-frequency syllables, and high-frequency words with high-frequency syllables. They observed both a word and a syllable frequency effect, the two effects being independent suggesting that the mental lexicon and the mental syllabary are independent stores. According to Levelt (1989), stored syllable programs are not completely fixed. A syllable can be pronounced with more or less force, shorter or longer duration, different kinds of pitch movement, and so on. These are free parameters, which have to be set from case to case.

Levelt's model of phonological and phonetic encoding clearly predicts our results. In particular, it clearly predicts faster word-naming latencies (at least for words with unambiguous initial syllables) when one of the syllables of the targets to be named is preactivated by the prime stim- ulus. The phonological encoder takes the word BALCONY and produces the following phonological word:

$$
\left(\left(\left(/ \mathrm{b} /{ }_{\text {on }} / \mathfrak{a} / /_{\mathrm{nu}} / 1 /{ }_{\text {co }}\right)_{\sigma \mathrm{s}}\left(/ \mathrm{k} / /_{\text {on }} / \partial /_{\text {nu }}\right)_{\sigma \mathrm{w}}\left(/ \mathrm{n} / /_{\text {on }} / \mathrm{i} /{ }_{\text {nu }}\right)_{\sigma \mathrm{w}}\right) \Sigma\right) \mathrm{W}
$$

It delivers a syllabified sequence of segments, together with a stress pattern over the syllables (cf. Roelofs, 1994, 1996). This representation describes BALCONY as a phonological word (W) consisting of three syllables $(\sigma)$ making up a foot $(\Sigma)$. The stressed first syllable $(\sigma \mathrm{s})$ consists of the onset $/ \mathrm{b} /$, the nucleus $/ \mathfrak{a} /$, and the coda $/ 1 /$. The unstressed second syllable $(\sigma \mathrm{w})$ consists of the onset $/ \mathrm{k} /$ and the nucleus $/ \partial /$. The third syllable consists of the onset $/ \mathrm{n} /$ and the nucleus $/ \mathrm{i} /$. Finally, the phonetic encoder takes this representation and produces the corresponding articulatory program, ['bæ1] [k $\partial]$ [ni]. This representation describes BALCONY in terms of the syllable programs ['bæl], [k $\partial$ ], and [ni], the first syllable to be pronounced louder or longer than the second and the third ones. Consider now the case of ambisyllabic words such as BALANCE. According to Levelt's model, the phonological encoder takes BALANCE and produces the corresponding phonological word. In that case, the stressed first syllable can consist of the onset $/ \mathrm{b} /$ and the nucleus $/ \mathfrak{r} /$, plus or minus the ambisyllabic consonant $/ \mathrm{l} /$, which belongs to both the stressed first syllable and the unstressed second syllable.

In order to explain the results of Experiment 4, we have to modify Levelt's model in order for the phonetic encoder to take this representation and to produce the two possible corresponding articulatory programs, ['bæ]

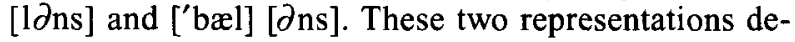
scribe the ambisyllabic word BALANCE in terms of the

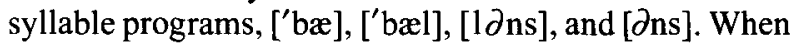
a match is found, the articulatory program is selected and executed, leading to overt speech. As already said in the introduction, the term ambisyllabic has been employed by phoneticians, phonologists, and psycholinguists to describe consonants that are considered to belong to both a preceding and a following syllable at the same time, as in words such as BALANCE, COMING, and so forth. It has been observed that no clear break between the syllables is perceptible in these cases, and that the intervocalic consonants in this context have a special behavior. The notion of ambisyllabicity has been taken as an argument against the boundary approach to the syllable (see, e.g., Selkirk, 1982). Although some linguists have tried to show that the assumption of ambisyllabicity is unnecessary, the present results show the psychological reality of this notion, as well as how subjects syllabify these ambisyllabic words.

\section{Syllable Chunks or Schemas?}

Theories of speech production hold two different views of the syllable (see Sevald, Dell, \& Cole, 1995, for a review). The first view is that syllables are chunks thiat specify their phonological content. Words are stored as strings of syllables, and each syllable is represented by a symbol that indicates its sounds. The second view is that 
syllables are schemas (or frames) that specify an abstract structure independently of its phonological content (e.g., CVC). For instance, the chunk view holds that syllables such as $/ \mathrm{sit} /$ and $/ \mathrm{bed} /$ are simply different chunks, because the sounds are different; but in the schema view they are similar, because they share the same structure (a CVC structure here). Priming experiments conducted by Meijer (1994) and Romani (1992) have shown that the word's structure can be primed. Sevald et al. also reported results that support the idea that the abstract structure of syllables is represented. They demonstrated an advantage for repeating the initial structure (e.g., KEM TIL.FER), but this effect was the same for repeating both content and structure (e.g., TIL TIL.FER). This suggests that the benefit may be due to repeating abstract structure only. Therefore, the results of our present experiments could be due either to the repetition of particular syllable strings or to the repetition of syllable structure. In other words, these results could support either the chunk view or the schema view of the syllable. Further work must address this possibility by teasing out phonological/orthographic priming from structural priming.

\section{Conclusion}

In summary, the results seem to support the hypothesis that speech production, on the level of execution, is organized primarily in syllable-sized units. The masked priming technique, combined with word naming, provides evidence for the psychological importance of syllable units in English. Furthermore, the results obtained with ambiguous words have shed light on how people syllabify these words.

\section{REFERENCES}

ADAms, M. J. (1981). What good is orthographic redundancy? In O. L. Tzeng \& H. Singer (Eds.), Perception of print: Reading research in experimental psychology (pp. 197-221). Hillsdale, NJ: Erlbaum.

ANDERSON, J., \& JoNES, C. (1974). Three theses concerning phonological representations. Journal of Linguistics, 10, 1-26.

BeLL, A., \& Hooper, J. B. (1978). Issues and evidence on syllabic phonology. In A. Bell \& J. B. Hooper (Eds.), Syllables and segments (pp. 3-22). Amsterdam: North-Holland.

Bradley, D. C., Sanchez-Casas, R. M., \& Garcia-Albea, J. E. (1993). The status of the syllable in the perception of Spanish and English. Language \& Cognitive Processes, 8, 197-233.

Brown, A. S. (1991). A review of the tip-of-the-tongue experience. Psychological Bulletin, 109, 204-223.

Brown, R., \& MCNeILL, D. (1966). The "tip of the tongue" phenomenon. Journal of Verbal Learning \& Verbal Behavior, 55, 325-337.

Bruck, M., Treiman, R., \& Caravolas, M. (1995). The syllable's role in the processing of spoken English: Evidence from a nonword comparison task. Journal of Experimental Psychology: Human Perception \& Performance, 21, 469-479.

ButLer, B., \& HaINS, S. (1979). Individual differences in word recognition latency. Memory \& Cognition, 7, 68-76.

CoRINA, D. P. (1992). Syllable priming and lexical representations: Evidence from experiments and simulations. In D. P. Corina (Ed.), Proceedings of the 14th Annual Conference of the Cognitive Science Society (pp. 779-784). Hillsdale, NJ: Erlbaum.

Crompton, A. (1981). Syllables and segments in speech production. Linguistics, 17, 663-716

Cutler, A., Mehler, J., Norris, D., \& Segui, J. (1986). The syllable's differing role in the segmentation of French and English. Journal of Memory \& Language, 25, 385-400.

Derwing, B. L. (1992). A "pause-break" task for eliciting syllable boundary judgments from literate and illiterate speakers: Preliminary results for five diverse languages. Language \& Speech, 35, 219-235.

Eriksen, C. W., Pollack, M. D., \& Montague, W. E. (1970). Implicit speech: Mechanism in perceptual coding? Journal of Experimental Psychology, 84, 502-507.

FaLLOWS, D. (1981). Experimental evidence for English syllabification and syllable structure. Journal of Linguistics, 17, 309-317.

Ferrand, L., \& Grainger, J. (1992). Phonology and orthography in visual word recognition: Evidence from masked nonword priming. Quarterly Journal of Experimental Psychology, 42A, 353-372.

FerRand, L., \& Grainger, J. (1993). The time course of orthographic and phonological code activation in the early phases of visual word recognition. Bulletin of the Psychonomic Society, 31, 119-122.

FerRand, L., \& GraingER, J. (1994). Effects of orthography are independent of phonology in masked form priming. Quarterly Journal of Experimental Psychology, 47A, 365-382.

Ferrand, L., Grainger, J., \& Segui, J. (1994). A study of masked form priming in picture and word naming. Memory \& Cognition, 22, 431-441.

Ferrand, L., Segui, J., \& Grainger, J. (1996). Masked priming of word and picture naming: The role of syllabic units. Journal of Memory \& Language, 35, 708-723.

Forster, K. I., \& Chambers, S. (1973). Lexical access and naming time. Journal of Verbal Learning \& Verbal Behavior, 12, 627-635.

Francis, W. N., \& KučERA, H. (1982). Frequency analysis of English usage: Lexicon and grammar. Boston: Houghton Mifflin.

Frederiksen, J. R., \& Kroll, J. F. (1976). Spelling and sound: Approaches to the internal lexicon. Journal of Experimental Psychology: Human Perception \& Performance, 2, 361-379.

Fromkin, V. A. (1971). The non-anomalous nature of anomalous utterances, Language, $47,27-52$.

FRY, D. B. (1964). The function of the syllable. Zeitschrift für Phonetik, $17,215-221$

Fujimura, O., \& Lovins, J. B. (1978). Syllables as concatenative phonetic units. In A. Bell \& J. B. Hooper (Eds.), Syllables and segments (pp. 107-120). Amsterdam: North-Holland.

Grainger, J., \& Ferrand, L. (1994). Phonology and orthography in visual word recognition: Effects of masked homophone primes. Journal of Memory \& Language, 33, 218-233.

Grainger, J., \& Ferrand, L. (1996). Masked orthographic and phonological priming in visual word recognition and naming: Cross-task comparisons. Journal of Memory \& Language, 35, 623-647

Gussenhoven, C. (1986). English plosive allophones and ambisyllabicity. Gramma, 10, 119-141.

HENDERSON, L. (1982). Orthography and word recognition in reading. London: Academic Press.

HOOPER, J. B. (1972). The syllable in phonological theory. Language, 48, $525-540$

Jacobs, A. M., Grainger, J., \& Ferrand, L. (1995). The incremental priming technique: A method for determining within-condition priming effects. Perception \& Psychophysics, 57, 1101-1110.

JARED, D., \& SEIDENBERG, M. S. (1990). Naming multisyllabic words. Journal of Experimental Psychology: Human Perception \& Performance, 16, 92-105.

KAHN, D. (1976). Syllable-based generalizations in English phonology. Unpublished doctoral dissertation, MIT.

Klapp, S. T., Anderson, W. G., \& Berrian, R. W. (1973). Implicit speech in reading reconsidered. Journal of Experimental Psychology, 100, 368-374.

LEVELT, W. J. M. (1989). Speaking: From intention to articulation. Cambridge, MA: MIT Press.

LEVELT, W. J. M. (1992). Accessing words in speech production: Stages, processes and representations. Cognition, 42, 1-22.

LEVELT, W. J. M. (1993). Timing in speech production with special reference to word form encoding. In P. Tallal, A. M. Galaburda, R. R. Llinás, \& C. von Euler (Eds.), Temporal information processing in the nervous system: Special reference to dyslexia and dysphasia (An- 
nals of the New York Academy of Sciences, Vol. 682, pp. 283-295). New York: New York Academy of Sciences.

LeVELt, W. J. M., \& WheELDON, L. (1994). Do speakers have access to a mental syllabary? Cognition, 50, 239-269.

MacKAY, D. G. (1972). The structure of words and syllables: Evidence from errors in speech. Cognitive Psychology, 3, 210-227.

Mehler, J., Dommergues, J., Frauenfelder, U., \& Segui, J. (1981). The syllable's role in speech segmentation. Journal of Verbal Learning \& Verbal Behavior, 20, 298-305.

MeIJer, P. J. A. (1994). Phonological encoding: The role of suprasegmental structures. Unpublished doctoral dissertation, Nijmegen University.

MEYER, A. S. (1992). Investigation of phonological encoding through speech error analyses: Achievements, limitations, and alternatives. Cognition, 42, 181-211.

Pulgram, E. (1970). Syllable, word, nexus, cursus. The Hague: Mouton.

RAPP, B. C. (1992). The nature of sublexical orthographic organization: The bigram trough hypothesis examined. Journal of Memory \& Language, 31, 33-53.

RoELOFS, A. (1994). One-line versus off-line priming of word-form encoding in spoken word production. In A. Ram \& K. Eiselt (Eds.), Proceedings of the Sixteenth Annual Conference of the Cognitive Science Society (pp. 772-777). Hillsdale, NJ: Erlbaum.

RoELOFs, A. (1996). Serial order in planning the production of successive morphemes of a word. Journal of Memory \& Language, 35, 854-876.

ROMANI, C. (1992). The representation of prosodic and syllabic structure in speech production. Unpublished doctoral dissertation, The Johns Hopkins University.

SEgUI, J. (1984). The syllable: A basic perceptual unit in speech perception? In H. Bouma \& D. G. Bouwhuis (Eds.), Attention and performance $X$ : Control of language processes (pp. 165-181). Hillsdale, $\mathrm{NJ}$ : Erlbaum.

SeidenberG, M. S., \& McClelland, J. L. (1989). A distributed, developmental model of visual word recognition and naming. Psychological Review, 96, 523-568

SelKirK, E. O. (1982). The syllable. In H. van der Hulst \& N. Smith (Eds.), The structure of phonological representations (Pt. 2, pp. 337464). Dordrecht: Foris.

Sevald, C. A., Dell, G. S., \& Cole, J. S. (1995). Syllable structure in speech production: Are syllables chunks or schemas? Journal of Memory \& Language, 34, 807-820.

SHATTUCK-HuFNAGEL, S. (1979). Speech errors as evidence for a serial order mechanism in sentence production. In W. E. Cooper \& E. C. T. Walker (Eds.), Sentence processing: Psycholinguistic studies presented to Merrill Garrett (pp. 295-342). Hillsdale, NJ: Erlbaum.

Solso, R. L., \& JuEL, C. L. (1980). Position frequency and versatility of bigrams for two- through nine-letter English words. Behavior Research Methods \& Instrumentation, 12, 297-343.

SPOEHR, K. T. (1978). Phonological encoding in visual word recognition. Journal of Verbal Learning \& Verbal Behavior, 17, 127-142.

SPOEHR, K. T. (1981). Word recognition in speech and reading: Toward a single theory of language processing. In P. D. Eimas \& J. L. Miller (Eds.), Perspectives on the study of speech (pp. 239-282). Hillsdale, NJ: Erlbaum.

SPOEHR, K. T., \& Smith, E. E. (1973). The role of syllables in perceptual processing. Cognitive Psychology, 5, 71-89.

TAFT, M. (1979). Lexical access via an orthographic code: The basic orthographic syllabic structure (BOSS). Journal of Verbal Learning \& Verbal Behavior, 18, 21-39.

TAFT, M., \& FORSTER, K. I. (1976). Lexical storage and retrieval of polymorphemic and polysyllabic words. Journal of Verbal Learning \& Verbal Behavior, 15, 607-620.

Tousman, S., \& InHoff, A. (1992). Phonology in multisyllabic word recognition. Journal of Psycholinguistic Research, 21, 525-544.

Treiman, R., \& Danis, C. (1988). Syllabification of intervocalic consonants. Journal of Memory \& Language, 27, 87-104

Treiman, R., Straub, K., \& Lavery, P. (1994). Syllabification of bisyllabic nonwords: Evidence from short-term memory errors. Language \& Speech, 37, 45 60.

Treiman, R., \& Zukowski, A. (1990). Toward an understanding of English syllabification. Journal of Memory \& Language, 29, 66-85.
Wells, R. (1951). Predicting slips of the tongue. Yale Scientife Magazine, 26, 9-30.

WheELdon, L. R., \& Levelt, W. J. M. (1995). Monitoring the time course of phonological encoding. Journal of Memory \& Language, 34, 311-334

WuNEN, F. (1988). Spontaneous word fragmentations in children: Evidence for the syllable as a unit in speech production. Journal of Phonetics, 16, 187-202.

\section{NOTES}

1. Throughout this article, we use a dot to denote the syllable structure of unambiguous words.

2. A number of other principles of syllabification (such as the sonority contour principle, the stress principle, the maximum onset principle) have been proposed in some theories. Here it is not our intention to go into much more detail about these other principles of syllabification, but the reader is referred to the excellent review of Treiman and Zukowski (1990).

3. Throughout this article, we use brackets to denote syllable structure of ambisyllabic words (e.g., BA[L]ANCE).

4. Because it was not possible to construct pairs of nonwords with the same constraints as those for the words of Experiment 1 (sharing the first three phonemes but with different initial syllables), the nonword RTs were not included in the analysis.

5. The terms inhibition and facilitation are used here to refer to increases or decreases in RT and/or percent errors relative to an unrelated prime condition. However, see Jacobs, Grainger, and Ferrand (1995) for a discussion of alternative ways of interpreting these concepts.

6. According to Levelt and Wheeldon (1994), the term phonological coding refers to the process through which the speaker successively generates syllables in speech production. The final stage of this process, called phonetic encoding, consists of accessing articulatory units for each of these syllables in a mental syllabary.

\section{APPENDIX A Stimuli Used in Experiments 1-4}

Stimuli are taken from Bradley et al. (1993). In all cases, primary stress falls on the initial syllable and the following syllable is unstressed.

\begin{tabular}{ll} 
CV(C) Words & CVC Words \\
balance & balcony \\
calendar & calcium \\
palace & palpitate \\
salad & salvage \\
talon & talcum \\
helicopter & helmet \\
pelican & pelvis \\
filament & filter \\
willow & wilderness \\
dollar & dolphin \\
canopy & cancel \\
lanolin & lantern \\
sanity & sandal \\
menace & mention \\
penalty & pencil \\
penetrate & pendulum \\
senator & sentence \\
tenement & tendency \\
vinegar & vindicate \\
tonic & tonsil \\
hammer & hamper \\
similar & simple \\
massacre & masculine \\
desecrate & destitute \\
\hline &
\end{tabular}


APPENDIX B

Stimuli Used in Experiment 5

Stimuli are taken from Treiman and Danis (1988). In all cases, primary stress falls on the second syllable.

\author{
CV Words \\ demote \\ reversal \\ covert \\ vanilla \\ relaxing \\ dilemma \\ tomato \\ November \\ device \\ sarong \\ delicious \\ remember \\ recital \\ divorce \\ report \\ reveal \\ depend \\ demand \\ remorse \\ remain \\ retirement \\ carouse \\ select \\ relate
}

(Manuscript received October 10, 1995;

revision accepted for publication July 1, 1996). 